\title{
Convergence of Strategies and Technologies - Next Generation Biocosmeceuticals and Biopharmaceuticals Products
}

Pierre A Guertin*

Laval University, Quebec City, QC, Canada

\section{The Pharmaceutical Industry is bound to Find New Models}

This industry is currently facing unprecedented challenges-the post-global financial crisis era, the patent cliff and its corresponding loss of revenues, massive job cuts by Big Pharma in U.S., downsizing/ closing down of some research programs, (e.g., neurosciences), low approval rates of new molecular entities (NMEs), etc. [1-4]. Since its emergence a century ago, this industry has generally based its model of development for new products upon one main dogma, i.e., the 'onetarget-one-disease' principle for which, corresponding NMEs and monotherapies are the end result [5]. These challenges added to the sky-rocketing costs of drug development for each new NME (i.e., 1.32.3 billion dollars, on average) have made it unsustainable-the industry can't continue relying on this model for future innovation and sustained sales $[6,7]$

\section{The Cosmetics has its Own Challenges}

In parallel, the other multi-billion dollars business that is the cosmetics industry has also been facing significant problems. Originally dominated only by a few multinational corporations such as l'Oréal, Procter and Gamble, and Estée Lauder, their revenues have largely relied primarily on marketing rather than science-based efficacy. However, new factors (e.g., diversification of products such as anti-aging, skin whitening, men's products, etc.) and a few scandals (e.g., generalized use of chemicals suspected of endocrine disruption, carcinogenic effects, reproductive problems, etc.) have forced this industry to also review its model in recent years $[8,9]$.

\section{Common Strategies and Technologies on the Rise - Multi - Targets and Combined Active Ingredients}

For the pharmaceutical industry, increasing the life time of older products and off-patent molecules has clearly become a trend in response to recent challenges [10]. One way to achieve that has been with new drug combinations or so-called fixed-dose combination (FDC) products. In the specific therapeutic areas of asthma, HIV, cancer or diabetes, FDCs have played a pivotal role to achieve greater efficacy and sustained revenues (e.g., Atripla, Advair, Janumet', etc.). FDCs are products that comprise at least two (often more) active pharmaceutical ingredients (APIs) combined in a single dosage form with fixed doses. New intellectual property, comparable safety, increased compliance and efficacy, as well as sustained or increased revenues are associated with the 'multi-target' approach that constitute FDCs [10-13]. For other complex therapeutic areas such as CNS diseases and disorders, the trend is more recent. Nonetheless, as of 2013, FDCs have been shown to constitute $22 \%$ of the CNS pipeline in development according to a report published recently by Drug Development [12]. The rationale is simple-administration of more than one drug or molecule for treating a disease leads to multiple actions that can be additive or synergistic $[14,15]$. Comparable approaches are increasing been used by the cosmetic sector. Some dermatological products with anti-aging effects or against pathological problems such as chronic xerosis, psoriasis, and pruritus are now also relying on combinatorial approaches using clinically-proven ingredients with scientifically-demonstrated efficacy $[16,17]$. This relatively new use of science applied to cosmetic/ skin products has generated its own specialized line of products - cosmeceuticals. For cosmeceutical products that comprise, for safety reasons, mainly ingredients of organic origin, a corresponding terminology, biocosmeceuticals, has even been introduced recently [16].

\section{Concluding Remarks}

Using known and safe molecules for which demonstration of efficacy (scientifically and clinically) and additive or synergistic effects have been shown will undoubtedly support the development of innovative next generation products. For these two large industries, the cost-effectiveness of this combinatorial approach will also probably ease and accelerate the approval of new technologies that better meet the medical needs of patients and users.

\section{References}

1. Mukherjee S (2015) Three major trends driving layoffs in biotech and pharma BioPharmaDIVE.

2. Pain E (2011) A Pharma industry in crisis. Science.

3. Wegener G, Rujescu D (2013) The current development of CNS drug research Integrative Journal of Neuropsychopharmacology 16: 1687-1693.

4. Serry JS (2013) The Great neuro-pipeline brain drain and why Big Pharma has not given up on CNS disorders. Drug Discovery World 2013 fall.

5. Wermuch CG (2004) Multitargeted drugs: the end of the 'one-target-onedisease' philosophy. Drug Discovery Today 9: 826-827.

6. DiMasi JA, Hansen RW, Grabowski HG (2008) Misleading congress about drug development: Reply. Journal of Health Polit Policy Law 33: 319-324.

7. Mullard A (2014) New drugs cost US $\$ 2.6$ billion to develop. Nature Reviews Drug Discovery 13: 877.

8. Lopaciuk A, Loboba M (2013) Global beauty industry trends in the $21^{\text {st }}$ century Management knowledge and learning conference 1079.

9. http://www.davidsuzuki.org/issues/health/science/toxics/dirty-dozen-cosmetic chemicals/

*Corresponding author: Pierre A Guertin, Department of Psychiatry and Neurosciences, Laval University and Laval University Médical Center (CHU de Québec), 2705 Laurier Boulevard, RC-9800 (Neuroscience Unit), Québec City, QC, G1Y 2T4, Canada, Tel: 4185254444 48831; Fax: 418-654-2753; E-mail: pierre.guertin@crchul.ulaval.ca

Received May 10, 2016; Accepted May 10, 2016; Published May 12, 2016

Citation: Guertin PA (2016) Convergence of Strategies and Technologies - Next Generation Biocosmeceuticals and Biopharmaceuticals Products. J Bioanal Biomed 8: e139. doi:10.4172/1948-593X.1000e139

Copyright: (c) 2016 Guertin PA. This is an open-access article distributed under the terms of the Creative Commons Attribution License, which permits unrestricted use, distribution, and reproduction in any medium, provided the original author and source are credited. 
Citation: Guertin PA (2016) Convergence of Strategies and Technologies - Next Generation Biocosmeceuticals and Biopharmaceuticals Products. J Bioanal Biomed 8: e139. doi:10.4172/1948-593X.1000e139

10. Gupta H, Kumar S, Roy SK, Gaud RS (2010) Patent protection strategies. Journal Pharmaceutics and Bioallied Science 2: 2-7.

11. http://www.strategyr.com/MarketResearch/CNS_Therapeutics_Market_ Trends.asp

12. Kararli T, Sedo K, Bossart J (2014) Fixed-dose combinations-What's in the clinic. Drug Development.

13. Pourkavoos $\mathrm{N}$ (2012) Unique risks, benefits, and challenges of developing drugdrug combination products in a pharmaceutical industrial setting. Combination products in therapy 2: 2 .
14. Guertin PA (2009) Recovery of locomotor function with combinatory drug treatments designed to synergistically activate specific neuronal networks. Current Medicinal Chemistry 16: 1366-1371.

15. Mouthon F, Charveriat M, Deslys JP, Iris F (2015) Use of anti-connexin agents for modulating the therapeutic effect of psychotropic drugs. US patent 14/736,004

16. Dupont $E$, Léveillé $C$ (2010) De l'hydration au renouvellement cellulaire: vers une approche intégrale de l'antivieillissement. Cosmetics and Toiletries Journal 125: $1-22$ 